\title{
REPRESENTAÇÃO NEGATIVA DO ALUNO DA EDUCAÇÃO BÁSICA EM RELATÓRIO DE ESTÁGIO SUPERVISIONADO
}

\section{Wagner Rodrigues Silva* Eliane de Jesus Oliveira**}

Resumo: Neste artigo, investigamos representações negativas de alunos da educação básica, identificadas em relatórios elaborados como atividade avaliativa em disciplinas de estágio supervisionado obrigatório. Os relatórios pertencem a duas licenciaturas diferentes. Esta pesquisa está situada no campo indisciplinar da Linguística Aplicada. Para fundamentar a análise linguística dos dados, articulamos a Linguística Sistêmico-Funcional e a Teoria das Representações Sociais. Identificamos representações negativas do interesse, do comportamento e das habilidades dos alunos na escola de ensino básico.

Palavras-chave: Escrita acadêmica. Formação do professor. Linguística Aplicada.

\section{INTRODUÇÃo}

"N o contexto científico brasileiro, a formação de professores é objeto de investigação em diferentes campos do conhecimento. Na Linguística Aplicada (LA), campo de investigação indisciplinar em que situamos a pesquisa aqui relatada, evidenciamos um significativo crescimento de estudos a respeito dos usos da escrita por professores em formação inicial nas graduações em licenciatura (cf. OLIVEIRA, 2016; SILVA, 2014a, 2012).

Neste artigo, em consonância com recentes estudos da formação inicial de professores, desenvolvidos na LA, investigamos algumas representações negativas a respeito dos alunos da escola básica, produzidas por professores em formação inicial, aqui denominados alunos-mestre, na escrita de relatórios de es-

Universidade Federal do Tocantins (UFT) - Palmas - TO - Brasil. Bolsista de produtividade do CNPq. E-mail: wagnerodriguesilva@ hotmail.com

** Professora da Educação Básica no Tocantins - Palmas - TO - Brasil. E-mail: liadejesus1@yahoo.com.br 
tágio supervisionado, elaborados como trabalhos avaliativos finais do referido componente curricular obrigatório em licenciaturas brasileiras. Este artigo traz alguns resultados da pesquisa de mestrado acadêmico apresentada por Oliveira (2016) e foi desenvolvido no âmbito dos grupos de pesquisa Práticas de Linguagens (PLES), da Universidade Federal do Tocantins (UFT/CNPq), e Sistêmica Através das Línguas (SAL), da Pontificia Universidade Católica de São Paulo (PUC-SP/CNPq).

O artigo está organizado em três seções principais, além desta "Introdução", das "Considerações finais" e das "Referências". Em "Representação na literatura de referência", sintetizamos algumas contribuições teóricas utilizadas na análise dos dados, originárias do diálogo estabelecido entre a Linguística Sistêmico-Funcional (LSF) e a Teoria das Representações Sociais (TRS). Em "Caracterização dos documentos investigados", descrevemos os relatórios selecionados para esta investigação, produzidos em duas licenciaturas: Letras (habilitação em Língua Portuguesa e habilitação em Língua Inglesa) e Química. Por fim, em "Representações negativas de alunos da educação básica", exemplificamos a análise dos dados a partir de três excertos reproduzidos a partir dos relatórios investigados.

\section{REPRESENTAÇÃO NA LITERATURA DE REFERÊNCIA}

Na perspectiva gramatical sistêmico-funcional, a análise linguística se orienta por três metafunções da linguagem, a saber: ideacional (desdobrada nos componentes experiencial e lógico) interpessoal e textual, que são desempenhadas por componentes léxico-gramaticais, escolhidos a partir de sistemas linguísticos de referência para composição textual. Nos termos de Eggins (2004, p. 213), apresentamos as seguintes definições para as referidas metafunções:

- ideacional: "um significado sobre a realidade";

- interpessoal: "um significado sobre a interação";

- textual: "um significado sobre a mensagem".

A língua é composta por sistemas sociossemióticos por meio dos quais as pessoas interagem em contextos particulares. Em outros termos, a lingua é organizada e produz sentidos por motivações contextuais semiotizadas na materialidade linguística. A respeito das escolhas a partir de sistemas linguísticos disponiveis, Thompson (2014, p. 27, tradução nossa) esclarece:

[...] o termo "escolha" não necessariamente implica um processo consciente de seleção pelo falante: o que visamos descobrir através da análise funcional são as opções significado-expressão que estão disponiveis no sistema linguístico e os fatores que levam ofalante a produzir um enunciado particular e não outra em um determinado contexto.

Para investigarmos as representações negativas dos alunos da educação básica a partir da análise dos relatórios de estágio supervisionado, por exemplo, tomamos como referência o complexo contexto de elaboração desses trabalhos acadêmicos escritos. Portanto, consideramos algumas relações instauradas entres os domínios da escola básica e da universidade. As próprias representações 
investigadas resultam de interações entre os atores representantes dos referidos dominios sociais ${ }^{1}$.

As análises linguísticas realizadas na seção seguinte foram orientadas, predominantemente, pela metafunção experiencial da linguagem, a qual é focalizada mais diretamente nesta revisão da literatura acadêmica, não significando, portanto, desconsideração das demais metafunções. A metafunção experiencial se realiza por meio do Sistema de transitividade, responsável pela construção de nossas experiências no mundo exterior e interior à nossa consciência.

As categorias linguísticas do referido sistema, responsáveis pela materialização na oração gramatical são: processo (grupo verbal); participante (grupo nominal); e circunstância (grupo preposicional ou grupo adverbial). No Quadro 1, elencamos as categorias de processo e participante de forma mais detalhada. Os participantes estão atrelados aos diferentes tipos de processo, resultando em diferentes conteúdos semânticos conforme escolhas realizadas a partir dos sistemas linguísticos de referência (cf. EGGINS, 2004; HALLIDAY; MATHISSEN, 2014; SILVA, 2014a; THOMPSON, 2014).

Quadro 1 - Sistema de escolha da transitividade

\begin{tabular}{|c|c|c|c|}
\hline Processo & Subprocesso & Participante & \\
\hline \multirow{4}{*}{ Material } & Transformativo & PRINCIPAL & SECUNDÁRIO \\
\hline & Criativo & \multirow{3}{*}{ Ator } & \multirow{3}{*}{ Meta } \\
\hline & Intencional & & \\
\hline & Involuntário etc. & & \\
\hline \multirow{4}{*}{ Mental } & Perceptivo & \multirow{4}{*}{ Experienciador } & \multirow{4}{*}{ Fenômeno } \\
\hline & Emotivo & & \\
\hline & Cognitivo & & \\
\hline & Desiderativo & & \\
\hline \multirow{5}{*}{ Relacional } & Atributivo & Portador & Atributo \\
\hline & Identificativo & Característica & Valor \\
\hline & Intensivo & & \\
\hline & Possessivo & & \\
\hline & Circunstancial & & \\
\hline \multirow{3}{*}{ Verbal } & & \multirow{3}{*}{ Dizente } & Receptor \\
\hline & & & Verbiagem \\
\hline & & & Alvo \\
\hline Comportamental & & Comportante & \\
\hline Existencial & & Existente & \\
\hline
\end{tabular}

Fonte: Elaborado pelos autores.

1 Para maiores detalhes a respeito da noção de contexto na LSF, consultar Silva (2014b) e Silva e Espindola (2013). 
Nos documentos investigados, as representações negativas dos alunos da educação básica são identificadas, principalmente, a partir das escolhas lexicais para as funções de processo e participante, realizadas pelos alunos-mestre. Os quatro primeiros processos elencados no Quadro 1 são recorrentes nos relatórios analisados. As representações construídas tendem a particularizar alguns participantes e circunstâncias. Isso ocorre a partir do uso de formas pronominais e adverbiais na função gramatical de modalizadores, evitando representações generalizadas, o que evidencia a relevância da metafunção interpessoal na investigação. A referida metafunção auxilia-nos a compreender relações de proximidade ou de distanciamento entre os atores sociais envolvidos nos estágios supervisionados, a exemplo dos supervisores, alunos-mestre, professores preceptores e alunos da escola de ensino básico.

Essa abordagem sistêmico-funcional da análise linguística dos dados é complementada com o enfoque social da TRS, proposta, de acordo com Moscovici (2003 p. 79), para "descobrir como os individuos e grupos podem construir um mundo estável, previsivel”, a partir das interações entre distintos atores vinculados a diferentes domínios sociais. O objeto de estudo da TRS é o indivíduo em sociedade, na interação entre atores sociais e grupos ou entre grupos. Jodelet (2001, p. 22) define representação social como:

[...] uma forma de conhecimento, socialmente elaborada e partilhada, com um objetivo prático, e que contribui para a construção de uma realidade comum a um conjunto social. Igualmente designada como saber de senso comum ou ainda saber ingênuo, natural, esta forma de conhecimento é diferenciada, entre outras, do conhecimento científico. Entretanto, é tida como objeto de estudo tão legítimo quanto este, devido à sua importância na vida social e à elucidação possibilitadora dos processos cognitivos e das interações sociais.

As representações sociais têm como objetivo tornar familiar algo pouco conhecido. Elas são semiotizadas nos textos mediadores das interações cotidianas, resultados das escolhas linguísticas motivadas por aspectos contextuais. Segundo Moscovici (2003, p. 58),

[...] as representações que nós fabricamos - duma teoria científica, de uma nação, de um objeto, etc - são sempre o resultado de um esforço constante de tornar comum e real algo que é incomum (não-familiar), ou que nos dá um sentimento de não-familiaridade. E através delas nós superamos o problema e o integramos a nosso mundo mental e fisico, que é, com isso, enriquecido $e$ transformado. Depois de uma série de ajustamentos, o que estava longe, parece ao alcance de nossa mão; o que parecia abstrato, torna-se concreto $e$ quase normal.

Quando o aluno-mestre entra em sala de aula para desenvolver as atividades práticas do estágio supervisionado obrigatório, ele integra ao local de trabalho saberes conhecidos a partir de teorias acadêmicas. Após uma sequência de atividades pedagógicas elaboradas e implementadas, o aluno-mestre começa a (re) construir representações dos alunos da educação básica, tornando familiar algo que, de alguma forma, até então lhe era distante.

Há dois mecanismos interconectados responsáveis pela geração das representações sociais, conforme proposto por Moscovici (2003, p. 61): ancoragem e objetivação. A ancoragem "tenta ancorar ideias estranhas, reduzi-las a catego- 
rias comuns, colocá-las em um contexto familiar". A finalidade da objetivação, por sua vez, é:

[...] transformar algo abstrato em algo quase concreto, transferir o que está na mente em algo que exista no mundo físico. As coisas que o olho da mente percebe parecem estar diante de nossos olhos fisicos e um ente imaginário começa a assumir a realidade de algo visto, algo tangível (MOSCOVICI, 2003, p. 61).

$\mathrm{Na}$ escrita acadêmica reflexiva dos relatórios, a objetivação consiste na externalização, ou seja, na discursivização das compreensões a respeito dos alunos da educação básica, produzidas pelos alunos-mestre. Nas representações identificas nesta pesquisa, a ancoragem e a objetivação estão presentes quando os alunos são caracterizados a partir do comportamento em sala de aula e do interesse demonstrado pela disciplina e pelo conteúdo estudado.

Ancorar significa classificar ou nomear alguma coisa. De acordo com Moscovici (2003, p. 63), "significa que nós o confinamos a um conjunto de comportamentos e regras que estipulam o que é, ou não é permitido, em relação a todos os indivíduos pertencentes a essa classe". Essas classificações são feitas por meio de comparações entre pessoas ou coisas e protótipos aceitos socialmente como modelos. Podemos relacionar essa ideia às representações dos alunos da educação básica, quando são criadas antinomias no intuito de classificar os alunos como interessados ou desinteressados, por exemplo.

Ao enfatizar o comportamento e interesse dos alunos pelos conteúdos estudados em sala de aula, o aluno-mestre atribui relevância ao assunto discursivizado, afinal compartilha a experiência relatada com outros leitores do relatório. $\mathrm{Na}$ TRS, esse fenômeno corresponde ao processo de tematização (themata) que trata do assunto de debate público, algo que merece ser estudado, debatido, analisado, algo que é digno de se tornar tópico de discussão.

Conforme Marková (2006), o pensamento é, por natureza, antinômico. Ou seja, estamos gerando conceitos de algo em oposição a outro constantemente. A antinomia também está relacionada às representações das tradições do passado em relação ao presente. Os alunos-mestre tendem a mobilizar representações dos alunos do passado para determinar as representações contemporâneas dos alunos.

De acordo com Moscovici (2003), a TRS tem compromisso com a linguagem. Isso porque as representações são manifestadas pelo discurso. Segundo o mesmo autor, "é através dos intercâmbios comunicativos que as representações sociais são estruturadas e transformadas" (MOSCOVICI, 2003, p. 28). Jodelet (2001, p. 32) acrescenta que a comunicação "é o vetor de transmissão da linguagem, portadora em si mesma de representações”. Moscovici (2003, p. 28) ressalta ainda que:

Em todos os intercâmbios comunicativos, há um esforço para compreender o mundo através das ideias específicas e de projetar essas ideias de maneira a influenciar outros, a estabelecer certa maneira de criar sentido, de tal modo que as coisas são vistas desta maneira, em vez daquela.

Ao conceituar representações sociais, Franco (2004, p. 2) assevera que elas são manifestadas por meio da linguagem, o que mostra a relação desta com a comunicação, uma vez que a linguagem é utilizada para comunicar. A autora ainda diz que as representações sociais: 
São elaborações mentais construídas socialmente, a partir da dinâmica que se estabelece entre a atividade psíquica do sujeito e o objeto do conhecimento. Relação que se dá na prática social e histórica da humanidade e que se generaliza pela linguagem (FRANCO, 2004, p. 3).

Nos relatórios de estágio, as representações construídas pelos alunos-mestre podem remeter a outras imagens, diferentes das legitimadas no domínio acadêmico, da mesma maneira como podem reproduzi-las. Em outras palavras, os alunos-mestre podem construir representações a respeito dos alunos da educação básica de forma incongruente com os discursos legitimados e propagados na universidade. Portanto, se bem utilizado na formação inicial, o relatório de estágio contribui, inclusive, para um diálogo mais simétrico entre as instituições referidas, desconstruindo preconceitos propagados.

\section{Caracterização dos documentos investigados}

$\mathrm{Na}$ pesquisa realizada, foram investigados 118 relatórios de estágio, produzidos nas licenciaturas em Letras (habilitações em Língua Portuguesa e em Língua Inglesa) e em Química, pertencentes à Universidade Federal do Tocantins (UFT), campus universitário de Araguaina. A escolha das licenciaturas focalizadas se justificava pelo interesse em contrapor licenciaturas de diferentes áreas do conhecimento, na tentativa de compreendermos se havia especificidades nas representações produzidas pelos alunos-mestre em relação aos alunos da educação básica a partir dos relatórios escritos. Os resultados da pesquisa não nos permitiram confirmar a referida hipótese, ou seja, não identificamos especificidades das representações dos alunos conforme as diferentes licenciaturas focalizadas.

Os documentos selecionados foram produzidos entre os anos letivos de 2011 a 2013, todos disponíveis para consulta pública no Centro Interdisciplinar de Memória dos Estágios Supervisionados das Licenciaturas (Cimes). O recorte cronológico se justifica pela disponibilidade de documentos para consulta das mesmas turmas, produzidos em semestres letivos consecutivos, conforme exposto no Quadro 2.

Quadro 2 - Quantidade de relatórios por licenciaturas

\begin{tabular}{|l|l|l|l|l|l|}
\hline $\begin{array}{l}\text { Relatório } \\
\text { Lingua } \\
\text { Portuguesa }\end{array}$ & Quantidade & $\begin{array}{l}\text { Relatório } \\
\text { Lingua } \\
\text { Inglesa }\end{array}$ & Quantidade & $\begin{array}{l}\text { Relatório } \\
\text { Química }\end{array}$ & Quantidade \\
\hline I & 13 & I & 23 & I & 09 \\
\hline III & 15 & III & 08 & II & 14 \\
\hline IV & 17 & IV & 08 & III & 11 \\
\hline Total & 45 & Total & 39 & Total & 34 \\
\hline
\end{tabular}

Fonte: Elaborado pelos autores.

Os relatórios do Estágio Supervisionado II das habilitações em Língua Portuguesa e em Língua Inglesa não foram incluídos na investigação devido à indispo- 
nibilidade dos documentos da disciplina no Cimes. Ainda conforme o Quadro 2, a quantidade de relatórios de estágio da habilitação em Língua Inglesa é inferior à da disciplina da habilitação em Lingua Portuguesa. Isso se justifica pelo fato de as atividades práticas do Estágio III da Língua Inglesa serem desenvolvidas por trios de alunos-mestre, resultando em um único relatório para três alunos-mestre. No Estágio IV da mesma habilitação, houve também dois casos em que o estágio foi desenvolvido por trios de alunos-mestre. Esses agrupamentos ocorreram em acordos entre formador, responsável pela disciplina e alunos-mestre.

Para as exemplificações reproduzidas na próxima seção deste artigo, selecionamos excertos em que o aluno-mestre faz referência explicitamente ao aluno da educação básica, apresentando as próprias impressões acerca desse ator social. Nesse sentido, entendemos representação em termos funcionais, como significados construídos a partir de escolhas linguísticas pelos alunos-mestre, ao caracterizarem os alunos da educação básica no contexto interativo da sala de aula. As escolhas linguísticas, componentes funcionais, são feitas a partir dos conhecimentos ou saberes acionados pelos alunos-mestre ao se depararem com situações vivenciadas no estágio. A partir dessas escolhas, representações também são (re)construídas.

Os excertos analisados foram transcritos da forma como aparecem no relatório de estágio, portanto, algumas inadequações linguísticas na escrita reproduzida são evidenciáveis. Os excertos exemplificados são precedidos pelo número do estágio (Estágio I, II, III e IV), a licenciatura a que pertencem, o ano de produção e a seção do relatório de onde foram retirados.

Ao analisarmos os excertos, identificamos os processos em que o aluno da educação básica é representado na função de sujeito gramatical com itálico; o aluno-mestre na posição de sujeito oracional com sublinhado simples; os modalizadores marcadores da não generalização dos alunos com sụ̣!̣ịṇado.pọntịlhạado; e os demais modalizadores de negação com sublinhado duplo.

\section{Representações negativas de alunOS da eduCAÇÃo básica}

A análise dos dados mostrou uma grande divisa entre as representações dos alunos da educação básica: negativas e positivas (cf. OLIVEIRA, 2016). Nas negativas, objeto de investigação deste artigo, encontramos uma especificidade referente à não generalização das imagens construídas a respeito dos alunos da educação básica. Ao caracterizar os referidos alunos destacando aspectos negativos, o aluno-mestre pontua o que é ou não permitido na sala de aula.

O Exemplo 1 corresponde à representação negativa das habilidades. O aluno-mestre reconta os fatos ocorridos durante as observações em sala de aula e tenta apresentar argumentos que mostram seu posicionamento em relação aos fatos vivenciados. Diante da dificuldade apresentada pelos alunos na habilidade de leitura, o aluno-mestre começa a tomar consciência do que irá enfrentar nas regências de aula e do que, certamente, precisará fazer para proporcionar a aprendizagem dos alunos.

No relatório, o excerto do Exemplo 1 é precedido pela explicitação das séries em que foram realizadas observações na escola. Após o excerto, o alunomestre continua argumentando a respeito da importância da teoria para a 
atuação do professor em serviço, conforme discurso propagado no domínio universitário.

No Exemplo 1, identificamos as duas modalidades de reflexão sobre ação definidos por Perrenoud (2002): reflexão retrospectiva e prospectiva. Após analisar os desafios encontrados em sala de aula, o aluno-mestre reflete, prospectivamente, sobre possiveis estratégias para solucionar os problemas detectados (precisamos, desde já, pensarmos).

\section{Exemplo 1 - Representação negativa das habilidades}

Estágio I - Letras: Língua Portuguesa - 2011/2

Relatando as observações no ensino fundamental

O que chamou bastante atenção nessas três observações foi a enorme dificuldade que os alunos têm com a oralidade. Quando a professora solicitou que os alunos lessem, em voz alta, os textos que estavam sendo trabalhados para a realização da atividade, muịtọs se sentiram incapazes de lerem corretamente e, por esse motivo, não se manifestaram. Esse fato evidencia a necessidade de elaborar atividades que desenvolvam as habilidades de comunicação oral nas escolas. Por isso, nós, futuros docentes, precisamos, desde já, pensarmos em estratégias que possam contribuir para que esse quadro se modifique.

O aluno-mestre menciona o que mais lhe chamou a atenção nas primeiras observações. O atributo "a enorme dificuldade que os alunos têm com a oralidade" mostra o que mais mereceu destaque entre os acontecimentos ocorridos na aula. Ainda focalizando o atributo no primeiro complexo oracional, o processo relacional possessivo "têm" contribui para a caracterização dos alunos da escola básica, indicando a demanda existente no tocante à habilidade de leitura oral. Essa demanda foi constatada a partir da verbiagem ("que os alunos lessem, em voz alta, os textos que estavam sendo trabalhados para a realização da atividade") referente ao processo verbal "solicitou", que tem como participante dizente da ação "a professora". Essas escolhas linguísticas mostram os alunos-mestre apenas como expectadores dos acontecimentos, uma vez que estavam cursando o estágio obrigatório de observação de aulas.

O atributo "incapazes", ligado semanticamente pelo processo comportamental "sentiram", pontua de forma enfática a dificuldade apresentada pelos alunos da escola básica na habilidade de leitura. O modalizador "muitos" é usado para indicar que nem todos os alunos compartilham dessa mesma dificuldade. A incapacidade está gramaticalmente expressa pelo processo material "lerem", seguido da circunstância "corretamente". Por falta de uma boa desenvoltura na habilidade leitora dos alunos, os mesmos se recusam a desenvolver tal atividade em sala de aula.

Diante da dificuldade apresentada pelos alunos da escola básica com a habilidade de leitura, os alunos-mestre tentam se posicionar por meio do operador argumentativo por isso. Como futuros professores, os alunos-mestre se colocam como responsáveis pela mudança do processo de ensino e de aprendizagem dos alunos.

Ao tematizar a ausência da habilidade de leitura dos alunos da educação básica, visualizamos o processo de objetivação e tematização da TRS (cf. MOSCOVICI, 2003). O primeiro aparece quando o aluno-mestre relata algo percebido por 
ele em seu campo de atuação profissional (a falta de habilidade de leitura dos alunos). Já o segundo se refere ao assunto tematizado, ou seja, quando o aluno-mestre coloca esse assunto em pauta, pode estar sinalizando que é de suma importância voltar o olhar sobre o problema e buscar uma possivel solução.

O Exemplo 2 corresponde à representação negativa do comportamento. No primeiro complexo oracional, o aluno-mestre se compromete de forma enfática com o conteúdo exposto ("posso ressaltar"; "jamais esquecerei"). Dentre as turmas observadas, o aluno-mestre escolheu a que mais the chamou a atenção para discorrer no relatório. A escolha da turma se deu por causa do comportamento que os alunos da escola apresentaram dentro da sala de aula, o que resultou na representação negativa dos mesmos.

No relatório, após o excerto do Exemplo 2, o texto segue tematizando a quantidade de alunos de outra turma, destacando também a indisciplina discente, assim como realizado no excerto em análise.

\section{Exemplo 2 - Representação negativa do comportamento dos alunos}

Estágio I - Química - 2013/2

Convívio com a sala de aula

Durante toda a observação do estágio supervisionado I na sala de aula, posso ressaltar uma em especial, a $3^{a}$ série do Ensino Médio vespertino, essa jamais esquecerei, as quais foram feitas anotações no meu caderno de campo como a bagunça dos alunos na sala de aula, em que, de instante em instante, a professora era obrigada a interromper a aula para chamar a atenção deles, mas logo em seguida começavam a conversar novamente. Entre eles haviam çrcạ de .cinço.a șęs alunos, que realmente estavam interessados na aula. A professora tenta interagir com a turma com perguntas a respeito do conteúdo, mas mụuịtọs deles não dão à mínima.

O grupo verbal "posso ressaltar", que desempenha a função de processo verbal, tem como dizente o próprio aluno-mestre, que se apresenta pela forma elíptica na primeira pessoa do singular. O alvo, "a $3^{a}$ série do Ensino Médio vespertino", é retomado por meio do pronome demonstrativo "essa", precedido pelo modalizador "jamais". Esse modalizador antecede o processo mental no futuro do presente "esquecerei". A escolha léxico-gramatical do modalizador, juntamente com a do processo citado, mostra que a estada do aluno-mestre nessa turma foi marcante, pois ficará guardada na memória. Não pela turma em si, mas pela indisciplina verificada.

Os modalizadores "cerca de cinco a seis" e "muitos deles" fortalecem a ideia de não generalização dos alunos da escola básica. Tanto no Exemplo 2 quanto em outras ocorrências dos dados, há sempre uma tentativa incessante do professor preceptor em controlar a indisciplina dos alunos. Na maioria das vezes, essas tentativas parecem vãs.

O Exemplo 3 corresponde à representação negativa do interesse. Esse discurso da falta de interesse pela disciplina e pelos conteúdos estudados é recorrente nas licenciaturas focalizadas e em todos os relatórios de estágio (I, II, III e IV). O aluno-mestre tende a representar negativamente os alunos da educação básica no período de observação, seja no Estágio I, em que ele apenas observa as aulas, 
seja no período de regência, no qual o aluno-mestre primeiramente observa aulas do professor preceptor e, após algumas observações, ministra aulas.

No texto original, o aluno-mestre tece comentário acerca do material pedagógico utilizado nas aulas de Língua Inglesa. Após o excerto do Exemplo 3, o aluno-mestre dá continuidade com uma citação de Rajagopalan (2003) sobre os motivos que podem levar os alunos a ter interesse em aprender a Lingua Inglesa numa escola pública brasileira. Apresenta algumas sugestões para melhorar o ensino na disciplina, tais como: transformação no ensino de língua, professores capacitados/qualificados na área, diversidade nas abordagens no ensino de língua, entre outras.

\section{Exemplo 3 - Representação negativa do interesse dos alunos}

Estágio I - Letras: Língua Inglesa - 2011/2

Concepções pedagógicas

Foi possivel perceber, que o interesse dos alunos nas aulas de Língua Inglesa era caótico, pois apenas algunş alunos se preocupavam em aprender e adquirir conhecimento. Os alunos só se interessavam quando certas atividades ou textos iriam cair na prova e quando havia alguma atividade com visto valendo nota.

O primeiro complexo oracional do Exemplo 3 é iniciado pelo grupo verbal "foi possivel perceber", que desempenha a função de processo mental perceptivo. Esse processo evidencia que os fatos relatados são, inicialmente, reconstruídos pelo aluno-mestre no mundo das ideias.

Ainda no primeiro complexo oracional, os alunos da escola básica são representados negativamente pela ausência de interesse apresentado. O julgamento negativo é construído por meio do atributo "caótico". A justificativa para a representação negativa é marcada pelo uso do operador argumentativo "pois", seguido por uma oração que corrobora para a representação negativa dos alunos ("apenas alguns alunos se preocupavam em aprender e adquirir conhecimento").

O aluno-mestre utiliza a forma pronominal "alguns" como modalizador, para particularizar os alunos mencionados. Mais uma vez, portanto, não generaliza o comportamento descrito.

No segundo complexo oracional, o aluno da educação básica aparece como agente interessado pelas atividades propostas, porém a representação negativa é explicitada por meio da forma adverbial "só", que apresenta um aluno preocupado apenas em adquirir notas.

Nos excertos aqui exemplificados, identificamos as seguintes escolhas linguísticas responsáveis pela particularização das representações construídas do aluno da educação básica: "alguns", "aqueles", "cerca de", "outros", "muitos". Essas escolhas são usadas para distinguir os alunos da educação básica, marcando a não generalização das representações construídas a respeito dos discentes.

\section{CONSIDERAÇÕES FINAIS}

A maioria das representações negativas dos alunos da educação básica foi construída a partir do momento em que os alunos-mestre observaram aulas dos professores preceptores na instituição de ensino receptora dos estagiários das 
licenciaturas. Certamente, isso se justifica pelo fato de os alunos-mestre evitarem tematizar aspectos negativos das aulas por eles ministradas na escola, uma vez que os relatórios são utilizados como instrumentos de avaliação do estágio obrigatório. Nesse sentido, durante a própria regência de aulas, os alunos-mestre enfatizam, por exemplo, metodologias e materiais didáticos por eles utilizados em resposta aos desafios identificados previamente, durante a observação de aulas.

Identificamos uma tendência de os alunos da educação básica serem representados nos relatórios de estágio a partir do interesse por eles manifestado pela disciplina escolar, do comportamento em aula e das habilidades demonstradas, daí as três categorias analíticas descritas neste artigo: representação negativa do interesse, representação negativa do comportamento e representação negativa das habilidades.

Para justificar as representações negativas identificadas, podemos apresentar inúmeras razões interconectadas, mas salientamos duas principais, conforme recorrência evidenciada nos relatórios: 1. tradição das atividades escolares com pouca atratividade para os alunos da educação básica; e 2. repertório limitado de conteúdo disciplinar e de estratégias pedagógicas passíveis de serem utilizados por professores preceptores.

Destacamos as contribuições desta pesquisa para o trabalho pedagógico nas disciplinas de estágio de diferentes licenciaturas a partir da sintese dos dois encaminhamentos seguintes: 1 . os resultados compartilhados com professores em formação inicial podem contribuir para familiarizá-los com algumas demandas existentes no futuro local de trabalho; 2. a tematização das representações negativas com professores em formação inicial pode evitar a reprodução de preconceitos a respeito da escola básica, comumente propagados no domínio universitário. Em outros termos, as representações negativas identificadas podem se configurar como ecos de discursos acadêmicos desfavoráveis a respeito da escola básica, o que precisa ser descontruído no próprio contexto de formação inicial do professor.

Por fim, reforço aqui a tese defendida já há algum tempo em nosso grupo de pesquisa (PLES): os estágios supervisionados obrigatórios das diferentes licenciaturas são campos férteis de investigação científica para a LA. Os usos da escrita acadêmica nessas disciplinas correspondem a apenas um dos fenômenos passiveis de estudo pelos linguistas aplicados.

\title{
NEGATIVE REPRESENTATION OF BASIC EDUCATION STUDENT ON SUPERVISED PRE-SERVICE TRAINING REPORT
}

\begin{abstract}
We investigate basic education students' negative representations that were identified on reports produced as assessment activity on mandatory supervised pre-service training subjects. The reports belong to two different undergraduate teaching courses. This research is located on the antidisciplinary field of Applied Linguistics. To base the linguistics analysis of date, we have articulated the Systemic Functional Linguistics and the Social Representation Theory. We have identified negative representations of students' interest, behavior and skills in basic school.
\end{abstract}

Keywords: Academic writing. Teacher education. Applied Linguistics. 


\section{REFERÊNCIAS}

EGGINS, S. An introduction to Systemic Functional Linguistics. 2. ed. London: Continuum, 2004.

FRANCO, M. L. P. Representações sociais, ideologia e desenvolvimento da consciência. Cadernos de Pesquisa, v. 34, n. 121, p. 169-186, 2004.

HALLIDAY, M. A. K.; MATTHIESSEN, C. M. I. M. Halliday's introduction to Functional Grammar. 4. ed. London: Routledge, 2014.

JODELET, D. As representações sociais. Rio de Janeiro: EdUERJ, 2001.

MARKOVÁ, I. Dialogicidade e representações sociais: as dinâmicas da mente. Tradução Hélio Magri Filho. Petrópolis: Vozes, 2006.

MOSCOVICI, S. Representações sociais: investigações em psicologia social. Petrópolis: Vozes, 2003.

OLIVEIRA, E. J. Representações de alunos da escola básica em relatórios de estágio supervisionado produzidos por professores em formação inicial. 2016. Dissertação (Mestrado em Letras: Ensino de Língua e Literatura)-Universidade Federal do Tocantins, Araguaína, 2016.

PERRENOUD, P. A prática reflexiva no oficio de professor: profissionalização e razão pedagógica. Porto Alegre: Artmed, 2002.

SILVA, W. R. Reflexão pela escrita no estágio supervisionado da licenciatura: pesquisa em linguística aplicada. Campinas: Pontes Editores, 2014a.

SILVA, W. R. Considerações sobre contexto de cultura na Linguística SistêmicoFuncional. In: XVII Congresso Internacional da Associação de Linguística e Filologia da América Latina - ALFAL, 2014, João Pessoa. Estudos Linguísticos e Filológicos. João Pessoa: Idéia, 2014b. p. 1991-2003.

SILVA, W. R. Letramento do professor em formação inicial: interdisciplinaridade no estágio supervisionado da licenciatura. Campinas: Pontes Editores, 2012.

SILVA, W. R.; ESPINDOLA, E. Afinal, o que é gênero textual na Linguística Sistêmico-Funcional? Revista da ANPOLL, v. 1, n. 34, p. 259-307, 2013.

THOMPSON, G. Introducing Functional Grammar. 3. ed. London: Routledge, 2014.

Recebido em janeiro de 2016.

Aprovado em maio de 2016. 